\title{
Reaching the palace
}

I've reached the palace. Resplendent, white, no sign of life, clinical love: when the harbingers of overwhelming pain scour the walls leaving no trace of before, no clue to after, only a sign of impending doom,

a palliative binge. No visitors! Half-fright, half-dead, this is the sick room where ache enacts fractals of agony, when the nerve fires and fires, crying wolf, and the brain-hag marshals what it has and, every time, I stand at attention.

In love with allodynia, abraded connection and false flag, $\mathrm{O}$ signalman, bury me release! Throes: wracked. Wrecked. Wrought with blunted thought and the kind of ascension meant for martyrs dying on the cross, this is loss, this is the exact naming of things, this is pain's manse and pain's program and I, suffused, ramshackle and beaten-down, have no threshold except the bridal one when pain steps across the gap as summons and takes me away, very far away.

- Shane Neilson

E-mail itchscratch@hotmail.com 


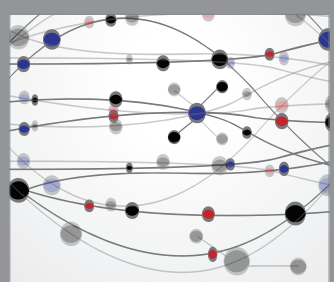

The Scientific World Journal
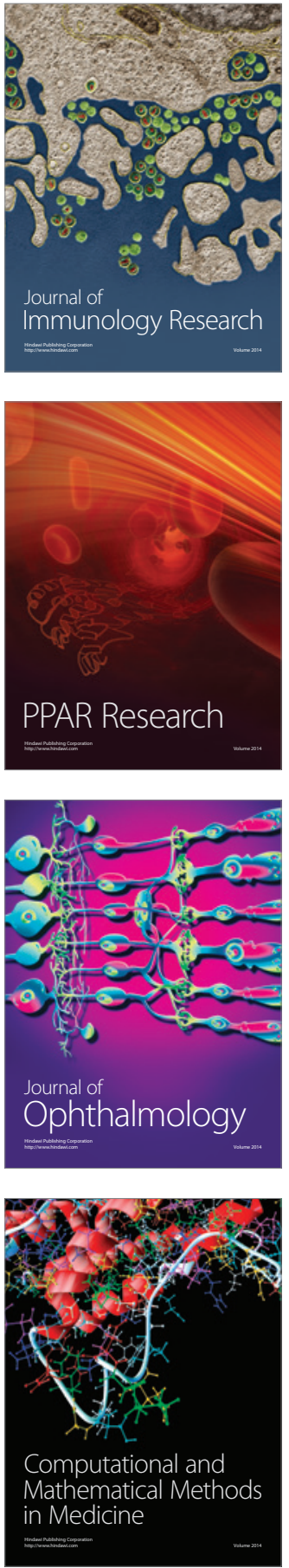

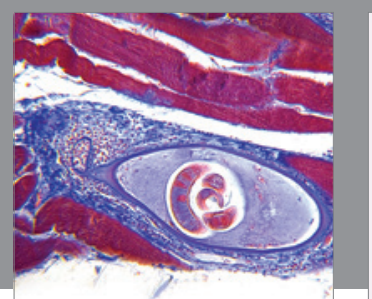

Gastroenterology Research and Practice

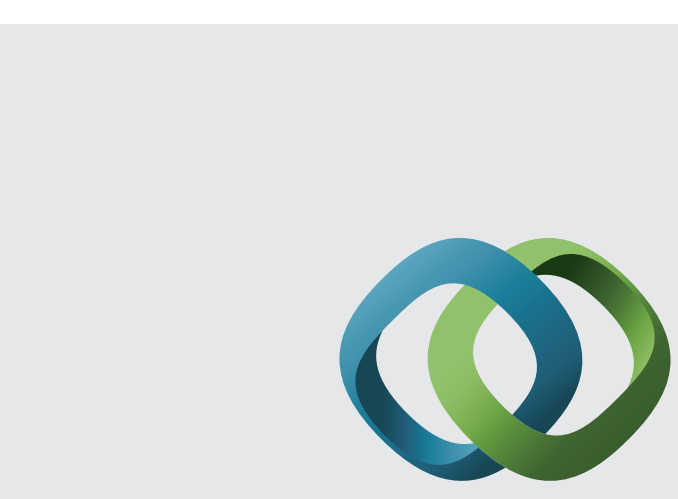

\section{Hindawi}

Submit your manuscripts at

http://www.hindawi.com

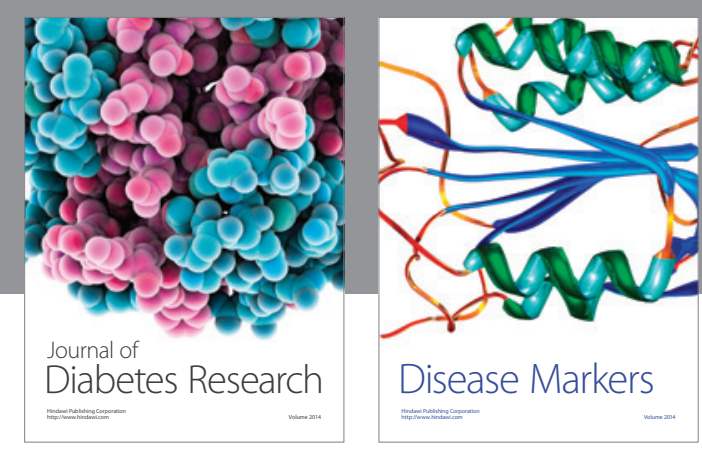

Disease Markers
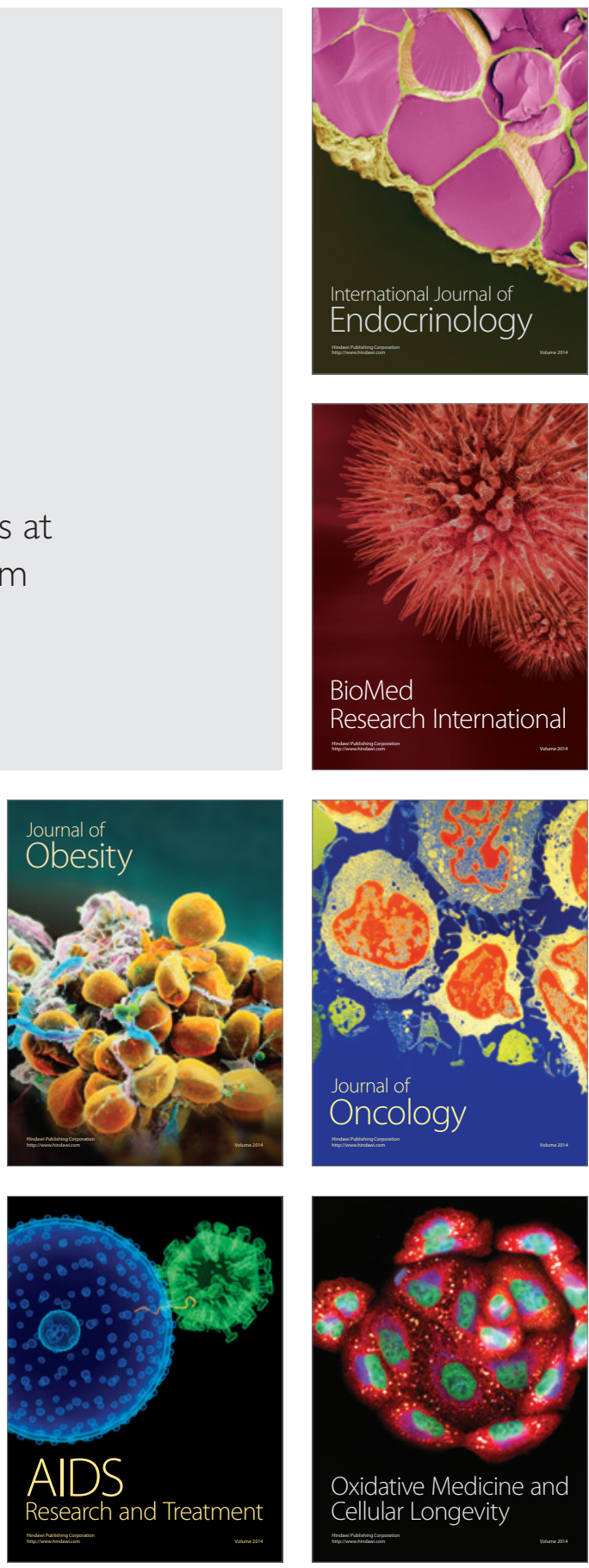